\title{
Results of routine screening for sexually transmitted diseases in Austria over a six-year period
}

\author{
D. FANTA,* W. GEBHART,* W. GROSS,† E. M. KOKOSCHKA, \\ J. SÖLTZ-SZÖTS,* AND J. THURNER* \\ From the *Epidemiology Unit, Department of Dermatology II, University of Vienna, and the \\ †Department of Dermatology, Krankenanstalt Rudolfstiftung, Vienna, Austria $\ddagger$
}

\section{Introduction}

The epidemiology of sexually transmitted disease (STD) changes rapidly with the increasingly rapid alterations in modern social behaviour and prevailing therapies, and with the changing biological activities of the causative agents. An important parameter in the control of STD is, therefore, an up-to-date knowledge of recent developments in this field. We have tried to analyse the situation in Vienna by pooling the results of screening of STDs, which, because of the local situation, is carried out by a rather heterogeneous group of medical institutions. General governmental care covers only small sections of the population and most of the patients are seen in hospitals, outpatient clinics, private referral laboratories, and private practice. Each of these institutions has its own special interest and its own, at least partly selected, patients.

\section{Study material and results}

In our study we collected the results of screening in four different groups of patients: (1) prostitutes under the health control of the governmental health service; (2) prostitutes who had been admitted to hospital for treatment of their STD; (3) outpatients of the second Viennese department of dermatology and venerology; and (4) patients sent to a microbiological laboratory by doctors in private practice.

LICENSED PROSTITUTES (GROUP 1)

Although the prostitutes comprise only a small group of patients they provide a useful indicator

¥In co-operation with the Ludwig Boltzmann Institute for Research on Infectious Venereodermatological Diseases

Address for reprints: J. Söltz-Szöts, Allgemeines Krankenhaus des Stadt Wien, II Universitats-Hautklinik, 9 Alserstrasse 4, A-1090 Vienna, Austria

Received for publication 20 November 1978 of the epidemiology of STDs owing to the broad spectrum of their sexual activities. The licensed Viennese prostitutes are under strict health authority control and if they do not attend for their obligatory weekly test they lose their licence. The total number in this professional group has increased from 548 in 1971 to 570 in 1977, indicating a balanced state. Nevertheless, there is a marked fluctuation in the incidence of STDs (Table 1).

Based on approximately 30000 tests a year the prostitutes' control authority found a significant decrease in the classical venereal diseases in this group. The incidence of gonorrhoea, which had reached a peak in 1971, when 199 out of 548 prostitutes had acquired the disease, decreased to 98 out of 570 cases among women in 1977. In 1971 only one case of syphilis was found but in 1974 and in 1977 the figures were 11 and two cases respectively.

Table 1 Number of cases of syphilis and gonorrhoea in licensed Viennese prostitutes (group 1)

\begin{tabular}{lrrr}
\hline & \multicolumn{2}{c}{ Year } & \\
\cline { 2 - 4 } & 1971 & 1974 & 1977 \\
\hline Gonorrhoea & 199 & 175 & 98 \\
Syphilis & 1 & 11 & 2 \\
Total no. of cases & 548 & 556 & 570 \\
\hline
\end{tabular}

HOSPITALISED PROSTITUTES (GROUP 2)

Since 1972, 1200 licensed as well as unlicensed amateur prostitutes with gonorrhoea have been admitted to hospital for repeated cultural, serological, cytological, and clinical investigations to evaluate the incidence of simultaneously existing STDs (Söltz-Szöts and Kokoschka, 1973) (Table 2).

Oral gonorrhoea does not seem to be a major problem among Viennese prostitutes, since only $8 \%$ of all patients with gonorrhoea (group 2) had positive pharyngeal culture results. An increase in the incidence of syphilis of from $1.5 \%$ to $5 \%$ was also observed in this group. 
Table 2 Other STDs occurring simultaneously in 1200 prostitutes with gonorrhoea (group 2)

\begin{tabular}{llc}
\hline & \multicolumn{2}{c}{ Year } \\
\cline { 2 - 3 } \cline { 2 - 2 } Other STDS & $1972 / 73$ & $1976 / 77$ \\
\hline Oral gonorrhoea & $(\%)$ & $(\%)$ \\
Syphilis & $\mathrm{NK}$ & 8 \\
Trichomoniasis & $1 \cdot 5$ & 5 \\
Candidosis & 35 & 56 \\
Condylomata acuminata & $15 \cdot 5$ & 43 \\
Pediculosis pubis & $2 \cdot 5$ & 1.6 \\
Scabies & $\mathrm{NK}$ & 1.5 \\
\hline
\end{tabular}

NK not known

A more pronounced increase was found in the incidence of trichomoniasis and candidosis between 1972 and 1977, although the same diagnostic procedures were applied. The incidence of trichomoniasis increased from $35 \%$ to $56 \%$ and that of candidosis from $15.5 \%$ to $43 \%$ in prostitutes with gonorrhoea in group 2. In contrast, the incidence of condylomata acuminata and scabies was again found to be lower in recent years than in 1972 and 1973 (Table 2).

OUTPATIENTS (GROUP 3 )

In the STD unit of the second department of dermatology in Vienna, where in Austria mainly dermatological patients are seen, more than 12000 patients with STDs attended for medical advice in the last six years (Table 3 ).

Gonorrhoea was detected in $21 \%$ of male and $16 \%$ of female patients in group 3; syphilis occurred in $11 \%$ and $7.5 \%$ respectively. The figures for trichomoniasis and candidosis differ greatly from those shown for the prostitutes, the reason for this being the non-random selection of patients referred to the clinic. Of all female patients $22 \%$ had candidosis and $9 \%$ trichomoniasis; the percentage in male patients was much lower at $6 \%$ and $2.5 \%$ respectively. Genital herpes was observed in $5.6 \%$ of the patients. Interestingly enough, chancroid was found in five cases in 1977 after a

Table 3 Final diagnoses of 1200 patients $(7500$ male and 4500 female) attending the STD unit (group 3)

\begin{tabular}{llc}
\hline Diagnosis & $\begin{array}{l}\text { Men } \\
(\%)\end{array}$ & $\begin{array}{l}\text { Women } \\
(\%)\end{array}$ \\
\hline Gonorrhoea & 21 & 16 \\
Syphilis & 11 & $7 \cdot 5$ \\
Trichomoniasis & $2 \cdot 5$ & 9 \\
Candidosis & 6 & 22 \\
Herpes genitalis & $5 \cdot 6$ & $1 \cdot 5$ \\
Condylomata acuminata & 9 & 5 \\
Pediculosis & $1 \cdot 5$ & 1 \\
Scabies & $9 \cdot 5$ & 14 \\
Chancroid & 0.06 & \\
\hline
\end{tabular}

10-year period of complete absence in Vienna. So perhaps we will have to expect a new period of activity of this disease.

\section{PRIVATE MICROBIOLOGICAL LABORATORY PATIENTS (GROUP 4)}

Finally, 39435 patients were seen in a private laboratory, to which they were referred for cultural diagnosis by dermatologists in private practice. Gonorrhoea was confirmed in $83.4 \%$ of the male and $76.7 \%$ of the female patients after the doctor had suspected this on clinical and microscopical grounds. On the other hand, only $0.6 \%$ and $1 \%$ of male and female patients respectively were found to have gonorrhoea when their doctor had suspected a non-specific STD. The additional information provided by culture tests confirmed only about $1.6 \%$ of cases after experienced investigators had made a diagnosis of gonorrhoea on the basis of the Gram-stained smears.

Trichomoniasis was detected in $8 \%$ of male and $14.8 \%$ of female patients with gonorrhoea and in $8.6 \%$ and $38 \%$ respectively when a non-specific STD was diagnosed by the practitioner. Candidosis predominantly occurred in female patients; $31 \%$ of female patients with a discharge and $5.8 \%$ of male patients had candidosis compared with no cases when gonorrhoea was suspected.

\section{Discussion}

In Vienna, as in other countries (Wallin, 1978), there has been a marked decrease in the number of cases of gonorrhoea since 1971. Although the same methods of investigation have been used the number of cases of condylomata acuminata, scabies, and genital herpes are at about the same level or have decreased slightly. Chancroid reappeared in Vienna in 1977 after a long period of absence.

From these trends in Vienna, we conclude that efforts to control gonorrhoea and syphilis have been successful and should be continued. More attention, however, should be directed towards measures against the increasing incidence of trichomoniasis and candidosis. In addition, some rare venereal diseases-such as chancroid-might reappear locally in the near future. These conditions should, therefore, be included in the training of doctors and students.

\footnotetext{
References

Söltz-Szöts, J., Kokoschka, E. (1973). Treatment of gonorrhoea with penicillin, cephaloridine and doxycycline. British Journal of Venereal Diseases, 49, 177-180.

Wallin, J. (1978). Sexually transmitted diseases. The present situation in Sweden. British Journal of Venereal Diseases, 54, 24-27.
} 